\title{
Copyleft e licenças criativas de uso de informação na sociedade da informação
}

\section{Clóvis Montenegro de Lima}

Doutor em administração de empresas na Fundação Getulio Vargas - SP (2000) e doutor em ciência da informação na Universidade Federal do RJ (2005).

E-mail: clovis.mlima@uol.com.br

\section{Rose Marie Santini}

Doutoranda em comunicacão e cultura na UFRJ

e em ciência da informaçã̃o no IBICT-UFF.

E-mail: mariesantini@gmail.com

\section{Resumo}

Neste trabalho se discutem algumas licenças criativas de uso de informação: Free Document Licenses (FDL) e Creative Commons (CC). As formas colaborativas de produção, disseminação e uso de informação, particularmente aquelas que usam a Internet, requerem novos enfoques da propriedade intelectual e do direito autoral. A produção colaborativa pode-se construir sob licenças para usar e recriar livremente produções anteriores. É possivel imaginar a dispensa da proteção legal do copyright, tornando idéias, software, músicas, imagens e textos livres e acessíveis a todos. A redução do controle político e econômico não visa apenas a facilitar 0 acesso aos bens, mas também a liberar a inovação e 0 desenvolvimento econômico. Conclui-se que as licenças criativas apresentam potencialidades e limitações. Contudo, constituem poderoso agente de mudança social e econômica, pois advertem para a inadequação dos sistemas de copyright e de propriedade intelectual na sociedade da informação.

\section{Palavras-chave}

Direito autoral. Licenças criativas de uso de informação. Free Documents License. Creative Commons.

\section{Creative licenses for information use in information society}

\section{Abstract}

This article discusses some creative licenses for information use, Free Document Licenses - FDL and Creative Commons - CC. The collaborative forms of production, dissemination and use of information, particularly those that use the Internet, request new focuses of the intellectual property and copyright. The collaborative production can be built by this licenses for free use and for recreating former productions. It is possible to imagine the dismissal of the copyright legal protection, turning ideas, software, music, images and texts free and accessible to all. The reduction of the political and economical control seeks to facilitate the access to the goods, but also to liberate the innovation and the economical development. The creative licenses present potentialities and limitations. However, they constitute a powerful agent of social and economical change, because they are a reminder of the inadequacy of copyright and intellectual property systems in the information society.

\section{Keywords}

Copyright. Creative license for information use. Free Document Licenses. Creative Commons.

\section{INTRODUÇÃO}

Neste artigo, discutem-se os conceitos de copyleft e de licenças criativas de uso de informação e outros bens imateriais, como forma inovadora de relação contratual entre produtores e usuários que emerge principalmente no contexto do uso das tecnologias de informação e comunicação. As licenças criativas são discutidas em contraponto à propriedade intelectual, mas se garante ao autor o direito moral de reconhecimento social pelo produto do seu trabalho.

A diferença conceitual e material entre, de um lado, o copyleft e a licença criativa e, de outro, a propriedade intelectual pode ser compreendida, por exemplo, nos desenvolvimentos de softwares. Os defensores do modelo proprietário pensam que a base da criatividade é a propriedade intelectual privada: sem ela, não haveria incentivo para a produção de inovações. Sob esta perspectiv, só há interesse em criar, inovar e produzir, se houver garantia de retorno privativo do investimento.

Os defensores dos softwares livres, como Barbrook (2003), Silveira (2006) e Stallman (2000), entendem que liberdade e compartilhamento são as bases da criatividade e inovação. Argumentam a partir de acontecimentos históricos e destacam que grandes avanços de criação e inovação são resultado de múltiplos fatores, mas que certamente acumulação de saber e seu livre compartilhamento são elementos importantes na determinação dos ritmos de criação, inovação e produção de bens imateriais.

Nossa época produz e reproduz formas singulares de relações sociais e econômicas, particularmente a produção colaborativa de bens imateriais, de saberes e de informação por pessoas que se comunicam por meio da Internet. Cabe destacar, dentre estas singularidades, o desenvolvimento do sistema operacional GNU/Linux e a construção compartilhada de conteúdos na Wikipédia [1].

É importante ressaltar que os bens imateriais, os saberes e a informação não possuem duas das características econômicas mais importantes dos bens materiais: a escassez e o desgaste pelo uso. Os bens materiais, para serem produzidos em quantidade, requerem estoque de recursos materiais que são finitos e que sofrem o fenômeno da escassez. 
O software pode ser copiado muitas vezes e, para ser reproduzido, requer apenas meio adequado. $\mathrm{O}$ seu valor tende a aumentar em função do crescimento do número de usuários. Além disso, quando se compartilha saber ou informação, não se perde aquilo que possui. A velocidade no desenvolvimento e a qualidade dos softwares livres parecem comprovar que pode ser obtida maior criatividade possível quando se compartilha informação e se produz de modo colaborativo.

\section{A INTELIGÊNCIA COLETIVA NA PRODUÇÃO DA SOCIEDADE DA INFORMAÇÃO}

O capitalismo moderno e industrial, centrado sobre a valorização de grandes massas de capital fixo material, é cada vez mais rapidamente substituído por um capitalismo pós-moderno e pós-industrial, centrado na valorização de um capital fixo dito imaterial. $O$ trabalho de produção material, mensurável em unidades de produtos por unidade de tempo, é substituído por trabalho dito imaterial, ao qual os padrões clássicos de medida não se aplicam.

O trabalho imaterial repousa sobre capacidades expressivas e colaborativas que não se podem ensinar, sobre a vivacidade presente no uso dos saberes que faz parte da cultura do cotidiano. É aquilo que Marx chama de General intellect, que torna acessíveis saberes e conhecimentos, ao mesmo tempo que fornece capacidade de interpretação e comunicação. Os trabalhadores do capitalismo pós-moderno e pós-industrial devem entrar no processo de produção com a bagagem cultural que adquirem fora do trabalho (GORZ, 2005).

A fonte mais importante da criação de valor é o saber vivo que está nas bases da inovação, comunicação e auto-organização. O trabalho do saber vivo é, sobretudo na economia em rede, o trabalho de produzir a si mesmo. Todo participante do trabalho em rede sincroniza-se continuamente com os outros, e o resultado do processo coletivo excede a soma das partes. Pierre Lévy (1993) chama este processo de "inteligência coletiva".

Lévy (1993) compara a inteligência coletiva a um coro polifônico improvisado. Este paradigma se aplica por excelência às comunidades virtuais da Internet, mas é, ao menos potencialmente, o modelo que está presente em toda produção colaborativa. Os produtores podem se apropriar dos meios de produção e fazer sua gestão. Os meios de produção se tornam potencialmente apropriáveis e suscetíveis de serem compartilhados.

Quando mais o trabalho apela aos talentos e às capacidades expressivas e colaborativas na produção, mais essas capacidades tendem a exceder seu uso limitado em uma tarefa determinada. O colaborador inclina-se a demonstrar que vale mais do que realiza profissionalmente e investe sua dignidade no exercício gratuito, fora do trabalho, de suas capacidades. É assim que, por exemplo, programadores de computadores demonstram suas habilidades no desenvolvimento de softwares livres.

Gorz (2005) observa que a pesquisa privada quase sempre tem como objetivo principal permitir que quem a realiza possa erguer um monopólio do conhecimento que proporcione rendimento exclusivo. $\mathrm{O}$ rendimento esperado conta mais do que o uso social do conhecimento produzido. Com investimentos em inovações e custosas campanhas de propaganda, toda empresa visa a chegar antes das outras à consolidação de posição monopolista.

Marketing e propaganda podem produzir valores simbólicos, estéticos e sociais. Associados às inovações, tornam obsoletos os produtos existentes e conseguem para a empresa um mercado que durante algum tempo é protegido contra a concorrência. Sempre se trata de transformar a abundância ameaçadora em uma nova forma de escassez e, assim, atribuir aos produtos valor mercantil incomparável, particular e único de obras de arte, que não possuem equivalente e podem ser postas à venda por preços exorbitantes.

O valor, no sentido econômico de valor de troca, aplica-se às mercadorias, ou seja, aos bens e aos serviços que são produzidos em vista de sua troca comercial. O que não é produzido pelo trabalho humano, assim como o que não se pode produzir, ou ainda não é permutável nem destinado à troca, não tem valor econômico. É o caso das riquezas naturais, como o sol e a chuva, que não se podem produzir, nem delas se pode apropriar. É principalmente o caso dos bens comuns a todos e que não podem ser divididos nem trocados por nada, como o patrimônio cultural.

Gorz (2005) adverte que, se não podem ser apropriadas ou valorizadas, as riquezas naturais e os bens comuns podem ser confiscados pelo viés das barreiras artificiais que reservam o uso delas aos que podem pagar um direito de acesso. A privatização das vias de acesso permite transformar as riquezas naturais e o patrimônio cultural em "quase mercadorias", que proporcionam renda aos vendedores de direitos de acesso, cujo controle é a forma privilegiada de capitalização das riquezas imateriais.

Os saberes são parte integrante do patrimônio cultural, são competências comuns da vida cotidiana. É sobre esta base de competências comuns que se constroem as competências profissionais certificadas. Os conhecimentos são o produto das interações e das comunicações entre as pessoas, contudo o capital não pode deixar de fazer funcionar o conhecimento como se este fosse um capital, apropriando-se, valorizando e subsumindo esta força produtiva.

O conhecimento como força produtiva é um bem que, em grande parte, resulta de atividade coletiva não remunerada. 
O conhecimento é "inteligência coletiva", cultura comum, saber vivo e vivido. Ele pode ser compartilhado à vontade, gratuitamente, especialmente por meio da Internet. O conhecimento pode ser reproduzido em quantidades ilimitadas por um custo desprezível e compartilhado sem ter de passar pela forma-valor. Assim, a principal fonte de valor é suscetível de ser subtraída à apropriação privada.

Gorz (2005) afirma que a novidade está no fato de que o conhecimento, separado de todo produto no qual esteve ou está incorporado, pode exercer, em si mesmo e por si mesmo, ação produtiva na forma de softwares. O conhecimento pode organizar e gerir interações complexas entre grande número de pessoas e de variáveis; pode conceber e conduzir máquinas, instalações e sistemas de produção flexíveis, ou seja, desempenhar o papel de capital fixo, substituindo o trabalho vivo por trabalho acumulado.

O custo marginal dos softwares é pequeno. Neles o conhecimento pode economizar muito mais trabalho do que custou, em proporções gigantescas. Isto significa que, se o conhecimento é fonte de valor, ele destrói muito mais valor do que serve para criar. $\mathrm{O}$ conhecimento economiza quantidades imensas de trabalho social remunerado e, conseqüentemente, diminui, ou mesmo anula, o valor de troca monetária de um número crescente de produtos e serviços.

O conhecimento abre a perspectiva de uma economia da abundância, em que a produção requer cada vez menos trabalho imediato, e distribui cada vez menos meios de pagamento. $\mathrm{O}$ valor de troca dos produtos tende a diminuir e causar a redução do valor monetário da riqueza total produzida, assim como a redução do volume de rendimentos. A economia da abundância tende por si só à economia da gratuidade e às formas de produção e uso fundadas no compartilhamento e na reciprocidade. O capitalismo pós-industrial é a crise do capitalismo em seu sentido mais estrito (GORZ, 2005).

A experimentação de outros modos de vida, de trabalho e de linguagem nos interstícios de uma sociedade pós-industrial que se desagrega pode funcionar como meio de resistência e de crise da legitimação do controle que o capital exerce sobre os corpos, os espíritos e sobre os meios de produção. Os constrangimentos e os valores da sociedade capitalista deixam de ser percebidos como naturais, liberando os poderes do desejo e da imaginação (GORZ, 2005).

\section{O COPYLEFT E AS LICENÇAS CRIATIVAS DE USO DA INFORMAÇÃO}

Barbrook (2003) afirma que a sociedade da informação em construção reproduz processos de produção colaborativos dos cientistas e pesquisadores que criaram a Internet. Pensando na rede para seu uso, inventaram modos de comunicação mediados por computador para compartilhar conhecimentos no espaço virtual: a "câmara dos comuns intelectual". O consumo passivo de informação se transforma em processo participativo de "criatividade interativa".

Os usuários das novas tecnologias digitais de informação e comunicação descobrem o potencial de compartilhar informações, conhecimentos e conteúdos. A comunicação em rede corrói profundamente as bases da indústria cultural, particularmente no que se refere à produção artificial da escassez pelo controle do acesso e do uso. A Internet evidencia a indústria cultural como algo histórico e social, e não como modo "natural" de produção e disseminação de bens imateriais.

As novas tecnologias estão revolucionando a economia da cultura, como mostra a crise da indústria da música. $O$ formato MP3 não apenas torna muito fácil a produção da cópia e sua disseminação através das redes P2P, das rádios on-line e dos telefones celulares, mas também muda a produção e a cultura de uso da música. Os usuários das tecnologias digitais são produtores e consumidores de música, com todas as suas facilidades (LIMA; SANTINI, 2005).

Os usuários das novas tecnologias digitais e da Internet estão revolucionando a produção cultural e artística. Na atualidade, qualquer pessoa pode usar a Internet para distribuir seus trabalhos de investigação, postar as canções que grava com seu grupo de música, ou difundir sem restrições os vídeos que realiza com sua câmera digital. Desaparecem, nestas circunstâncias, os intermediários culturais. Torna-se mais imediata a relação criador-usuário.

As novas tecnologias contribuem para que se questionem os fundamentos da forma-mercadoria e da lógica da intermediação capitalista. Outros metabolismos econômicos emergem, particularmente aqueles derivados da generosidade e da solidariedade. Na sociedade da informação, a propriedade intelectual dos bens imateriais se contrapõe aos interesses comuns. A produção de escassez artificial entra em conflito com a produção colaborativa e com o compartilhamento. O sistema de copyright parece não mais servir.

Barbrook (2003) advoga pelo desaparecimento da propriedade intelectual, na forma de copyright, e pela regulação da informação de modo libertário: o copyleft. [2]. Os produtores devem conservar sua capacidade de reivindicar a autoria do seu trabalho (direito autoral moral), mas todos devem ser autorizados a copiar e a usar livremente as informações segundo seus interesses e propósitos. Assim, liberdade de expressão é liberdade de não se submeter à forma compulsória de mercadoria.

O copyleft é uma relação contratual construída a partir da legislação do copyright, normalmente da mesma forma que 
qualquer licença tradicional de proteção dos direitos autorais entre o autor e quem o publica. São algumas cláusulas deste contrato que faz o copyleft diferente e merecedor de um nome especial. O copyleft pode ser definido como a licença que:

(1) autoriza a derivação de trabalhos subseqüentes de um trabalho original, sem a permissão do proprietário protegido por direitos autorais;

(2) concede a autorização para trabalhos derivados, requerendo que estes também sejam autorizados pela licença de copyleft do original.

O copyleft autoriza e assegura recursivamente um tipo de "liberdade" de uso (e para códigos de computador, necessariamente, o código-fonte aberto e a transparência também). As cláusulas especiais desta relação contratual formam uma espécie de coluna vertebral funcional de uma infinidade de licenças de uso, o que implica que o termo copyleft se refere a uma grande família de licenças criativas que têm as duas características básicas citadas anteriormente.

O copyleft é uma ferramenta para criadores de conteúdos com os seguintes objetivos:

(a) proteger os direitos do seu trabalho enquanto o dissemina amplamente;

(b) proteger contra a restrição do acesso ao trabalho, contra a sua vontade e além do que considera necessário como recompensa;

(c) assegurar que seus trabalhos não serão vulneráveis a ações legais ruinosas;

(d) criar ambientes de cultura livre, no qual seus trabalhos tenham liberdade de circulação e possam ser construídos de forma aberta.

Em 1984, Stallman, pesquisador do Massachusets Institute of Technology (MIT), lança manifesto em que propõe compartilhamento e cooperação no desenvolvimento de softwares. Quando ele começa a trabalhar no laboratório de inteligência artificial do Mit em 1971, o compartilhamento dos códigos-fonte dos softwares era um processo tão comum quanto o compartilhamento de receitas culinárias. A partir dos 1980, inicia-se o processo de fechamento do código-fonte dos softwares (STALLMAN, 2000).

Em 1985, Stallman cria a General Public License (GPL), para disseminar "permissões livres" aos programas de computador sob uma única condição: a de não colocar obstáculos à circulação dos programas modificados sob a licença GPL. Em relação a estes programas, não é necessário requerer autorização para acessar o seu "código-fonte", para obter cópia, modificá-lo e usá-lo com qualquer fim, inclusive distribuir os programas modificados.

Nos sites do movimento GNU [3] ou da Free Software Foundation [4] define-se software livre como "liberdade de os usuários executarem, copiarem, distribuírem, estudarem, modificarem e aperfeiçoarem o software". Eles se referem a quatro tipos de liberdade para os usuários dos softwares:

1. liberdade de executar o programa, para qualquer propósito;

2. liberdade de estudar como o programa funciona e adaptá-lo para suas necessidades. $\mathrm{O}$ acesso ao códigofonte é um pré-requisito para esta liberdade;

3. liberdade de redistribuir cópias de modo que o usuário possa colaborar com o seu próximo;

4. liberdade de aperfeiçoar o programa e liberar os seus aperfeiçoamentos, de modo que toda a comunidade se beneficie deles. $\mathrm{O}$ acesso ao código-fonte também é um pré-requisito para esta liberdade.

O General Public License (GPL) permite que os programas sejam distribuídos e reaproveitados, mantendo, porém, os direitos do autor, de forma a não permitir que essa informação venha a ser usada de maneira que limite as liberdades originais. A licença não permite, por exemplo, que o código possa ser apropriado por outra pessoa, ou que possam ser impostas restrições que impeçam a sua distribuição da mesma maneira que foi adquirido.

A GPL permite aos usuários do software redistribuir cópias modificadas de forma gratuita, ou comercial. Não impede a distribuição de programas com a cobrança de contrapartida monetária, mas não permite que algum modelo de comercialização retire estas liberdades. Uma questão crucial para que a licença possa ser considerada GPL é que não se pode cancelar ou anular aquelas quatro liberdades vinculadas ao programa. Esta medida visa claramente a impedir que se torne software proprietário.

A licença típica do software livre, GPL, é baseada na regra de que, quando se está redistribuindo um programa, não se pode negar as liberdades principais. Esta regra não entra em conflito com as liberdades; na verdade as protege. Seu objetivo é impedir que um programa produzido em colaboração venha a ser apropriado privadamente e dele se retirem possibilidades de colaboração. O copyleft permite liberar o que as licenças proprietárias proíbem.

A Free Software Foundation possui também uma licença criativa especial para documentos e textos denominada Free Documentation License (FDL) e inspirada na GPL. A FDL permite que conteúdos de páginas na Internet possam ser distribuídos e reaproveitados, mantendo, porém, alguns 
direitos autorais, sem permitir que essa informação venha a ser usada de maneira indevida. Uma das exigências da FDLé que o material tenha publicação em formato transparente para melhor se exercerem os direitos que a licença garante.

A FDL permite explicitamente a qualquer usuário do item licenciado copiar e distribuir essas cópias, inclusive recebendo compensação monetária por elas. Permite ainda locá-las e exibilas publicamente. Ela proíbe que se usem meios técnicos para impedir que pessoas que tenham acesso a qualquer cópia gozem dos mesmos direitos que quaisquer outros. Versões modificadas (traduções, por exemplo) podem ser incluídas, desde que o autor da modificação concorde em licenciar a versão pela FDL.

\section{AS LICENÇAS CREATIVE COMMONS}

Uma das mais populares iniciativas de regulação autônoma das formas de produção e uso de sistemas e conteúdos é concebida por Lessig (2005): o Creative Commons (CC) [5]. O CC tem por finalidade desenvolver licenças que possam ser usadas por qualquer pessoa ou organização, para que seus trabalhos venham a ser disponibilizados para uso, cópia, disseminação e recriação. A criação de uma rede contratual de produtores e usuários de sistemas e conteúdos permite que se compartilhem seus trabalhos pela Internet.

O Creative Commons é baseado na idéia de proporcionar instrumentos concretos (as licenças) aos criadores para que possam regular os usos de suas obras. Quer dizer, as licenças são instrumentos legais que permitem aos autores estabelecer os termos sob o quais querem compartilhar suas obras, deixando que outros as usem, copiem, distribuam e modifiquem, mantendo seu direito moral ao reconhecimento como criadores e proibindo, por exemplo, o uso comercial.

O Creative Commons cria opção de um meio-termo legal entre "todos os direitos reservados" dos contratos de direito autorais tradicionais e o domínio comum, e autores e artistas podem escolher como e o quanto desejam autorizar uso, cópia e recriação de suas obras. A iniciativa tem como finalidade principal discutir e construir um domínio comum das obras. A proposta de Lessig $(2005,2006)$ é mobilizar produtores e usuários de conteúdos na construção deste domínio comum e demonstrar a sua importância na produção cultural.

Creative Commons se posiciona como moderador das autorizações de uso e põe à disposição dos autores licenças $a$ la carte, cuja redação se incorpora ao site ou suporte da obra e onde se regulam os usos autorizados pelo autor com respeito à referida obra. Isto, evidentemente, também permite que autores decidam que sua obra passe ao domínio público imediato. As características destas licenças as tornam particularmente atraentes e úteis para aqueles autores novos que, desejando distribuir sua obra pela Internet, colocam-na à disposição para uso de forma gratuita (LEMOS, 2005).

É necessário entender o Creative Commons como dirigido principalmente a autores que têm interesse predominante na circulação ampla de sua obra. O CC também responde àqueles autores que possuem posições bem estabelecidas e querem opção de publicidade para suas obras desvinculadas da indústria cultural (editores, produtores e outros). As licenças criativas tocam um dos pontos mais sensíveis dos autores: sua relação, nem sempre pacífica, com as empresas que normalmente se apropriam da titularidade das obras. Usando a licença CC, o autor pode exercitar o "monopólio legal" criativo que a legislação reconhece.

O Creative Commons busca fomentar a reutilização criativa das obras, permitindo que o autor mantenha os direitos que considere oportuno. O CC põe à disposição dos autores em sua página da Internet formulários que permitem escolher as características de distribuição das suas obras. Uma vez preenchidos estes formulários, o sistema gera a licença em três formatos: resumo de uso autorizado, texto legal e versão digital com metadados que se pode usar para facilitar o trabalho dos "buscadores" na Internet.

O Creative Commons tem sido adaptado no Brasil. Especialistas da Escola de Direito do Rio de Janeiro e da Fundação Getulio Vargas trabalham com esta licença desde 2003. Há esforço no sentido de adaptar estas licenças criativas ao arcabouço jurídico nacional. Em 2004, o governo brasileiro anuncia oficialmente seu apoio à iniciativa, que se torna uma mobilização global, com a participação de mais de 30 países. A repercussão desta posição no exterior é tal que a revista Wired (2004), das mais importantes entre as que focam novas tecnologias, retrata o país como uma nação open source.

Um dos principais difusores da licença no Brasil, Ronaldo Lemos, afirma que a força motriz da iniciativa é a participação voluntária:

Só participa do Creative Commons quem quer, só autoriza alguns usos da obra quem quer. O mote é trazer de volta a possibilidade natural de compartilhamento de idéias que se esvai com as recentes modificações na legislação. Tudo para garantir a existência de um universo cultural comum com obras livres para serem acessadas, compartilhadas, redistribuídas e, se o autor permitir, também modificadas (LEMOS, 2005, p.264).

Toda vez que o autor emite uma licença Creative Commons que regule o uso de sua obra, estabelece relação contratual sobre direitos autorais. Os usuários de obras submetidas à licença CC vão supor sempre que a exploração dessa obra se realize sob os termos desta licença criativa. Uma vez divulgada uma obra, o CC torna difícil que o autor a retire de circulação. 
Considerando que o Creative Commons não é repositório de conteúdos, ou seja, não produz ou administra estoques de obras licenciadas, sendo apenas lugar de consulta sobre a autorização dos autores e de moderação da relação entre criadores e usuários, surge um importante hiato entre os lugares de publicação das obras e as suas licenças de uso. Cria-se, assim, a demanda por organização dos conteúdos licenciados criativamente de acordo com a cultura de produção e uso de conteúdos na Internet

\section{CONSIDERAÇÕES FINAIS}

O capitalismo pós-industrial se afir ma como capitalismo ao empregar um recurso copioso - a inteligência humana -, transformando a abundância potencial em escassez. Tal escassez é produzida mediante parcelamento do saber, impedimento de sua disseminação e socialização, e obrigação da forma de mercadoria para os produtos do saber, da inteligência e da sensibilidade.

Um bom exemplo da apropriação monopolista da bagagem cultural dos trabalhadores pode ser observado no uso e desenvolvimento de softwares proprietários, como o Windows, da Microsoft. Milhões de trabalhadores aprendem a usar exclusivamente este software com cópias piratas, e isto vira atributo funcional, além de contribuir para o desenvolvimento da tecnologia. Assim, as empresas não precisam investir em treinamento do uso destes programas, e a Microsoft fica com clientes usuários cativos.

É importante perceber que o modelo de mediação da indústria cultural, que contrata e remunera os produtores de conteúdo e controla o acesso aos seus produtos, tem pouco mais de cem anos e é uma produção histórica. As novas tecnologias digitais trazem extrema facilidade para a produção e disseminação de conteúdos, além do acesso à informação e aos bens imateriais. A cultura na sociedade da informação é uma cultura pósindustrial.

As formas colaborativas de produção, disseminação e uso de informação, particularmente aquelas que usam a Internet, requerem novos enfoques da propriedade intelectual e do direito autoral. A produção colaborativa pode se construir sob a "licença de uso" para usar e recriar livremente produções anteriores, sem autorização prévia específica. Fundam-se assim novos modos de produção e comunicação colaborativos, que rompem com as formas capitalistas de organização da produção.

É possível imaginar a total dispensa da proteção legal do copyright, tornando as idéias, a música, as imagens e os textos livres e acessíveis a todos. Cabe pensar em outros mecanismos para compensar a criatividade dos autores, artistas e cientistas, mas não há motivo para presumir que a criatividade depende da promessa de apropriação privada de lucros. A redução do controle econômico dos bens imateriais não visa apenas a facilitar o acesso, mas também a liberar a inovação e o desenvolvimento.

No contexto colaborativo, a propriedade intelectual dos produtos impede a continuidade do processo criador e não apenas a sua apropriação comum e universal por usuários. As licenças criativas correspondem à demarcação da autoria (direito moral), mas não reproduzem a forma das mercadorias capitalistas. As licenças criativas convidam à participação na produção, e não a mera escolha para consumo entre informações e bens culturais.

O copyleft e as licenças criativas de uso de informação são mais do que uma complementação das atuais leis de direitos autorais, atendendo àqueles que não querem suas restrições. Cabe observar que todas as licenças criativas apresentam potencialidades e limitações. Contudo, elas constituem poderoso agente de mudança social e econômica, principalmente porque advertem para a inadequação dos sistemas de propriedade intelectual e de copyright.

\section{Notas}

1- WIKIPEDIA. Disponível em: http://www.wikipedia.org/.

2. O termo copyleft vem de um trocadilho com duplo sentido em inglês, que substitui o right (direita ou direito, em inglês) de copyright por left, que em inglês significa esquerda ou pode se referir à conjugação no passado do verbo leave (deixar). Este trocadilho torna o copyleft um termo próximo à cópia autorizada. Outro trocadilho brinca com a famosa frase todos os direitos reservados, que sempre acompanha o símbolo das obras protegidas. Com o copyleft, all rights reserved torna-se all rights reversed (todos os direitos invertidos).

3- GNU. O sistema operacional GNU. Disponível em: < http://www. gnu.org/>. Acesso: em 23 jul. 2008.

4- FREE SOFTWARE FOUNDATION. FSF Free Software Licensing. Disponível em: <http://www.fsf.org/licensing >. Acesso: em 23 jul. 2008.

5- CREATIVE COMMONS. Creative Commons BR. Disponível em: <www.creativecommons.org.br >. Acesso: em 23 jul. 2008. 


\section{REFERÊNCIAS}

BARBROOK, Richard. A regulamentação da liberdade: liberdade de expressão, liberdade de comércio e liberdade de dádiva na rede. In: COCCO, G.; GALVÃO, A. P.; SILVA, G. (Org.). Capitalismo cognitivo: trabalho, redes e inovação. Rio de Janeiro: DP\&A, 2003.

BERRY, David M.; MOSS, Giles. The politics of the libre commons. First Monday, v. 11, n. 9, Sept. 2006. Disponivel em: $<$ http:// firstmonday.org/issues/issues11 9/berry/index.html > . Acesso em: 15 jul. 2007.

CASTELLS, Manuel. A sociedade em rede. 5. ed. São Paulo: Paz e Terra, 2001.

CHAUI, Marilena. Cultura e democracia: o discurso competente e as outras falas. São Paulo: Cortez, 1993.

DELEUZE, Giles; GUATTARI, Felix. Mil platôs: capitalismo e esquizofrenia. Rio de Janeiro: 34, 1995. v. 1.

DIBELL, Julian. We pledge allegiance to the Penguin. Wired Magazine, Nov. 2004.

GONZALEZ DE GOMEZ, Maria Nélida. Novos cenários políticos para a informação. Ciência da Informaç̧ão, v. 31, n. 1, p. 27-40, jan. 2002.

GORZ, André. O imaterial: conhecimento, valor e capital. São Paulo: Annablume, 2005.

GUATTARI, Felix. Revolução molecular: pulsações políticas do desejo. 3. ed. São Paulo: Brasiliense, 1987.

\section{Centelha, 1987.}

; NEGRI, Toni. Os novos espaços de liberdade. Lisboa:

HARDT, Michael; NEGRI, Toni. Império. 5. ed. Rio de Janeiro: Record, 2003.

Multidão: guerra e democracia na era do império. Rio de Janeiro: Record, 2005.

KROWNE, Aaron; PUZIO, Raymond. The fog of copyleft. First Monday, v. 11, n. 7, July 2006. Disponivel em: $<$ http://firstmonday. org/issues/issues11 7/krowne/index.html>. Acesso em: 15 jul. 2007.

LAZZARATO, Maurizzio; NEGRI, Toni. Trabalho imaterial: formas de vida e produção de subjetividade. Rio de Janeiro: DP\&A, 2001.

LEMOS, Ronaldo. $O$ 'creative commons' e as transformações da propriedade intelectual. In: BARBOSA FILHO, A.; CASTRO, C.; TOME, T. (Org.). Mídias digitais: convergência tecnológica e inclusão social. São Paulo: Paulinas, 2005.
LESSIG, L. Cultura livre: como a grande mídia usa a tecnologia e a lei para bloquear a cultura e controlar a criatividade. São Paulo: Trama, 2005.

The people own ideas. Disponível em: $<$ http://www. lessig.org/blog/archives>. Acesso em: 21 ago. 2006.

LEVY, Pierre. As tecnologias da inteligência. Rio de Janeiro: 34, 1993. . Cibercultura. Rio de Janeiro: 34, 1999.

LIMA, Clovis Ricardo Montenegro; SANTINI, Rose Marie. Trabalho imaterial, compartilhamento de informação e produção colaborativa na sociedade da informação. Revista Eletrônica de Biblioteconomia em Ciência da Informação, Florianópolis, n. 23, 2007. Epapers, 2005

. MP3: música, comunicação e cultura. Rio de Janeiro:

MAUSS, Marcel. Ensaio sobre a dádiva: forma e razão da troca nas sociedades arcaicas. In: SOCIOLOGIA e antropologia. São Paulo: Editora Pedagógica e Universitária Ltda., 1974. v. 2.

MIRANDA, Antonio. Sociedade da informação: globalização, identidade cultural e conteúdos. Ciência da Informação, Brasília, v. 29, n. 2, p. 78-88, maio/ago. 2000.

NEGRI, Toni. Cinco lições sobre império. Rio de Janeiro: DPA, 2003.

PRADO, Cláudio. Sinapse XXI: novos paradigmas em comunicação. In: BARBOSA FILHO, A.; CASTRO, C.; TOME, T. (Org.). Mídias digitais: convergência tecnológica e inclusão social. São Paulo: Paulinas, 2005.

SILVEIRA, Sergio Amadeu. A mobilização colaborativa e a teoria da propriedade do bem intangivel. 2005. Tese (Doutorado) - Universidade de São Paulo, São Paulo, 2005. Disponível em: < http://twiki. softwarelivre.org/bin/view/TeseSA/WebHome >. Acesso em: 21 mar. 2007.

. Propriedade intelectual, monopólios do conhecimento e software livre. In: CARVALHO, I. M. et al. (Org.) Gestão do conhecimento: uma estratégia empresarial. Brasília: SERPRO, 2006.

STALLMAN, Richard. O projeto GNU. DataGramaZero, Rio de Janeiro, n. 1, fev. 2000.

TORVALDS, Linus.; DIAMOND, D. Just for fun: the story of an accidental revolucionary. [s.l.]: Harper Business, 2001. 